\title{
Ambientes Digitais
}

\author{
Acir Mário Karwoski * \\ Julio Cesar Oliveira Bernardo**
}

BRAGA, Denise Bértoli. Ambientes digitais: reflexões teóricas e práticas. São Paulo: Cortez, 2013.

O livro de Denise Bértoli Braga, professora titular do Departamento de Linguística Aplicada da Unicamp, intitulado "Ambientes digitais: reflexões teóricas e práticas" é o sexto volume da Coleção "Trabalhando com... na escola", publicado pela Editora Cortez em 2013. O livro contém 148 páginas e divide-se em duas partes: a primeira voltada para a contextualização histórica e comportamental diante das Tecnologias de Informação e Comunicação - (TICs); e a segunda voltada para recursos e exemplos de aplicabilidade no ensino, especialmente o ensino de línguas.

Quanto à autora da obra, Denise Bértoli Braga é mestre em lingüística pela Unicamp e doutora em educação pela Universidade de Londres. Possui pós-doutorado pela Universidade de Monash, da Austrália. Conhecida no ambiente universitário e educacional, desde a década de 1990 a autora dedica seus estudos sobre as tecnologias digitais e seus impactos na linguagem e no ensino, especialmente no ensino de línguas estrangeiras. Atualmente, partindo da declaração de que "navegar é preciso", a autora tem se dedicado aos estudos acerca do potencial da tecnologia digital para a ampliação da participação social. Sem dúvida, a obra "Ambientes digitais: reflexões teóricas e práticas" traz inúmeras contribuições para as reflexões acerca do uso de tecnologias digitais não apenas na escola mas, também, na sociedade.

A autora, em nossa opinião e segundo declaração enviada voluntariamente por email aos autores da resenha pela professora Vera Menezes, da Faculdade de Letras da Universidade Federal de Minas Gerais (UFMG), "é uma das pioneiras em pesquisa sobre linguagem digital e aprendizagem mediada por computador. Adotei o livro "Ambientes Digitais" em minha última disciplina e ele proporcionou boas reflexões e discussões entre meus alunos. Escrito em linguagem adequada ao público jovem, este último trabalho de Denise Braga oferece aos seus leitores temas obrigatórios para quem acredita que "navegar é preciso".

Assim, conhecendo a autora e o que outros pesquisadores da área de lingüística aplicada pensam a respeito dela e de sua obra, decidimos organizar essa resenha visando à troca de experiências teóricas e práticas no contexto atual dos estudos e pesquisas acerca dos multiletramentos, especificamente sobre os ambientes digitais.

Logo em suas primeiras páginas, o livro é apresentado de maneira instigante pela professora Anna Christina Bentes (Coordenadora da Coleção). Instigante porque, segundo Bentes, "a obra encanta o leitor à primeira vista não só porque trata de um dos mais importantes temas para o contexto de ensino e aprendizagem no século XXI, mas, principalmente, porque discorre sobre esse tema colocando-o no centro do interesse do professor das mais diversas áreas." (p. 7). E, ainda, segundo Bentes, "esta obra nos ajuda a melhor compreender como esse "maravilhoso mundo novo", organizado por meio de tecnologias que mudaram $e$ continuarão mudando a vida em sociedade, já vem contribuindo de forma definitiva para o desenvolvimento de formas conjuntas de fazer conhecer, principal tarefa da escola e de todos os professores." (p. 12)

Posteriormente, na introdução, a autora do livro se propõe a refletir sobre as TICs e sua utilização, sobretudo em atividades voltadas para o Ensino Médio, destacando que, apesar desses recursos de aprendizagem estarem disponíveis na internet, são "sistematicamente ignorados" em propostas de livros didáticos (p.13). Sobre gêneros e discurso, a autora apresenta reflexões pertinentes no contexto de letramento, afirmando que "ensinar a ler e escrever é um trabalho conjunto, favorecido, mas não determinado, pelas práticas didáticas nas aulas de língua." (p.15). A autora mostra como mais flexível e adequado o conceito de "participação social" em oposição à "inclusão social", visto que pressupõe o respeito às especificidades culturais e, nesse ínterim, aponta a internet como caminho para ampliação dessa participação social. Alerta, no entanto, quanto à imprescindibilidade de sua utilização coerente que, segundo ela, permitirá a professores do Ensino Médio "em serviço ou em formação" estabelecer o desenvolvimento de competências na prática 
pedagógica.

No primeiro capítulo "Uma breve reflexão sobre a história da escrita" da Parte Um " $O$ professor frente aos novos recursos de ensino", a autora retoma Vygotsky quanto ao conceito de linguagem como ferramenta cognitiva que permite a construção da cultura e molda a mente humana segundo os parâmetros da inserção social vivenciada. A autora traça a história dos registros dos signos, perpassando pela evolução desde os tempos das cavernas e registros em placas de pedra ou argila. A autora contextualiza as diferentes formas de representações visuais à capacidade de suporte textual, bem exemplificando a partir do emprego de pergaminhos e papiros, chegando posteriormente ao formato do livro em papel, inovação que facilitou o registro e o acesso atual à informação. A autora detalha com eficácia processos do desenvolvimento evolutivo da escrita desde práticas medievais à efervescência da leitura em si, possibilitada e dinamizada a partir da separação visual das unidades lexicais. No universo entre a mesclagem da oralidade com a escrita com respectiva "hibridização" (p. 37), a autora ratifica que a análise do processo histórico gerador das práticas de letramento tradicionais ajuda a decifrar problemas recorrentes no cotidiano do ensino. Enfatiza, também, que profissionais tradicionalistas devem, por questão de sobrevivência, ceder lugar à viabilização de "novas práticas de leitura $e$ produção textual e passar a explorar novos modos de construção do conhecimento" (p. 38), comportamento que deve ser contínuo, sobretudo em cenários de letramentos digitais.

No segundo capítulo "Tecnologia da informação e comunicação e novos letramentos", a autora destaca a evolução pós-industrial e o surgimento da sociedade da informação, que permitiu a integração de linguagens diversas que culminaram em novos tipos de gêneros, composições textuais e práticas comunicativas: os novos letramentos (p. 39) da era digital. A autora destaca a criação de redes sem fio (wireless) que dinamizaram o processo comunicativo, agora sem limites de tempo e espaço, em ambiente de leitura inovador, marcado pela multimodalidade e hipertextualidade. A autora evidencia a possibilidade de o professor, diante da imensidão de recursos da internet, complementar livros didáticos ou até mesmo substituí-los em um novo contexto em que o aluno torna-se sujeito ativo de sua aprendizagem.

O terceiro capítulo "Alguns motivos para alento: tecnologia a serviço dos professores" é subdividido e direcionado a professores das diferentes áreas e a professores de línguas. Aos primeiros, a autora levanta uma série de possibilidades de suporte didático por meio da internet e afirma que de fato todos os docentes são instrumentos fundamentais na ampliação do repertório de letramento de seus alunos; e que o professor de línguas pode se tornar um aliado promissor num contexto construtivo de interdisciplinaridade. Aos professores de línguas, a autora menciona pertinentes benefícios para a aprendizagem. No caso de uma língua estrangeira, a internet possibilita o acesso a textos das mais variadas naturezas e assuntos, num processo interativo ilimitado e em um letramento recorrente e eficaz. Quanto ao ensino da Língua Portuguesa, a autora aponta a diversidade de gêneros nos ambientes virtuais e a interatividade global do aluno diante deles, atribuindo ao professor função de mediar, construir "pontes no nível linguístico $e$ cultural de forma a aproximar e facilitar a aquisição de gêneros e discursos escolares"(p. 53).

No quarto capítulo "Um alerta: navegar é preciso" a autora evidencia a potencialidade da internet enquanto espaço virtual de pesquisa, de aprendizagem e de interatividade social. Salienta que cabe aos educadores "delinear caminhos que permitam a formação de indivíduos menos ingênuos $e$ mais éticos" (p.57), deixando explícita a necessidade de adequação dos agentes envolvidos a um novo contexto social e tecnológico.

No quinto capítulo "Tecnologia e mudanças nos modos de ensinar e aprender", a obra traz reflexões interessantes da autora sobre o uso efetivo e não fictício de recursos digitais. A autora alerta para o fato de que "ser digital" não é garantia de "inovação", sendo preciso para tal a efetividade da transformação pedagógica. A autora subdivide este capítulo em três subcapítulos. Em "Da escola para vida real ou vice-versa" afirma que a realidade social dos alunos deve ser considerada na construção do itinerário pedagógico e formativo numa realidade em que o mais relevante é a gestão do conhecimento no que tange à formação de competências para posicionamentos críticos, construção reflexiva de habilidades e estratégias de autoformação levando o aluno a "aprender $a$ aprender" efetivamente. No subcapítulo seguinte "Aprendizagem baseada em casos e aprendizagem baseada em problemas", a autora ratifica a relevância da construção da aprendizagem a partir de situações da vida real, demandando que o aluno 
se torne o maior interessado e responsável por seu aprendizado. A autora ilustra essas situações de aprendizagem com complexos e fecundos exemplos, enfatizando a trans e a interdisciplinaridade. Este capítulo é concluído com um breve subcapítulo "Práticas de estudo independente", ocasião em que a autora apresenta a viabilidade de o professor selecionar endereços (sites) e estimular seus alunos a interagirem produtivamente com eles.

A Parte Dois "Muita coisa mudou... ou deveria..." tem como primeiro capítulo "Recursos oferecidos pelas ferramentas e ambientes digitais", quando a autora se propõe a discorrer sobre recursos possíveis para as práticas pedagógicas em rede. A autora demonstra o tom revolucionário da ascensão das TICs e da Web 2.0 para efetivação das iniciativas de ensino a distância. A autora reconhece o diferencial da portabilidade desses recursos, considerados por ela desenvolvimentos tecnológicos que possibilitam o surgimento do Ambiente Virtual de Aprendizagem (AVA), que veio incrementar o ensino além-muros, turbinando práticas educacionais a distância e ou complementando cursos presenciais. A autora descreve - e o faz com propriedade - dois AVAs de acesso livre na internet: O TelEduc e o Moodle, ilustrando com exemplos práticos de aplicabilidade e funcionalidade. Apresenta os AVAs como meios viáveis para construção colaborativa e coletiva do conhecimento enquanto ambientes que explicitamente evoluem os meios tradicionais de ensino. Deixa claro, no entanto, a necessidade de contínua mediação e intervenção do professor no processo de ensino e aprendizagem.

Nos cinco subcapítulos do capítulo seguinte "Ambientes e ferramentas da internet incorporados às práticas de ensino", a autora traz uma seleção de ferramentas oferecidas na rede compatíveis com processos interativos de aprendizagem. Sobre o "blog" a autora demonstra sua viabilidade na hospedagem de gêneros discursivos privilegiados com a tonalidade informacional e comunicacional aliada à utilização pedagógica, situação também demonstrada por meio de exemplos com projetos interdisciplinares. Ao dicionário on-line a autora atribui maior agilidade e precisão na utilização, com possibilidades de ampliação da consulta/pesquisa por meio de links e sublinks a partir de verbetes e respectivas definições, apresentando exemplos de aplicações práticas. Sobre tradutores automáticos no ensino de língua estrangeira, a autora faz ressalvas quanto a suas limitações técnicas, fazendo, no entanto, considerações sobre sua utilização adequada. A autora afirma que é possível aprender exatamente sobre os pontos de falha ou inexatidão dos próprios processos tradutórios, salientando que com a mediação precisa, de fato, são ferramentas viáveis ao ensino de língua estrangeira. A autora apresenta exemplo de aplicação a partir de uma pesquisa de mestrado, além de outros exemplos de aplicações possíveis, aliando o uso de vídeos em sala de aula ao trabalho com tradutores. Quanto ao Twitter, a autora aponta seus recursos e ilustra uma aplicação prática. Considera-o na prática de letramento digital, sobretudo pelo poder de acessibilidade e agilidade da informação, com a possibilidade hipertextual de indicação de links. Quanto ao Google.docs, a autora ressalta a capacidade de arquivamento de textos e a criação de documentos de forma colaborativa, forma "eficiente de construção de conhecimento no contexto on-line" (p. 116), também exemplificado com a Wikipédia. Nesse contexto, a autora traz um exemplo pertinente envolvendo a reconstrução de textos, o que também possibilita aos alunos a interação com gêneros textuais diferenciados daqueles do cotidiano escolar. Quanto às redes sociais, a autora reconhece a facilidade de, por meio delas, o professor poder fazer diagnósticos a partir do perfil dos seus alunos bem como possibilidade de formação de grupos sociais. A autora alerta, entretanto, para a facilidade da perda de foco, o que, segundo a autora, deve deixar o professor atento na mediação pedagógica. Como exemplo, apresenta-se o Facebook, sobre o qual a autora traz detalhes superficiais.

A autora encerra a Parte Dois com o capítulo "Finalizando", quando chama a atenção para o fato de que "a escolha de um determinado ambiente ou recurso digital deve ser avaliada em termos dos objetivos pedagógicos propostos..."(p. 125). A autora ainda enfatiza que a mediação digital "nas atividades de ensino e aprendizagem será produtiva se o professor levar em consideração" (p. 129) o objetivo, a ferramenta escolhida e o tipo de mediação, atentando-se para os critérios de avaliação.

Em suas "Considerações finais", a autora se justifica por ter optado a apresentar em seu livro um roteiro geral de embasamento para aplicações práticas ou estudos mais aprofundados, devidamente contextualizados com as TICs em um processo de sociedade em rede, cada vez mais globalizado. Instiga-se o professor à mudança, a sair de sua situação de conforto, a práticas de ensino construtivas e renovadoras, ainda mais quando em causa coletiva. A autora conclama, enfim, que 
"navegar é preciso", sobretudo no desbravamento da informação rumo ao êxito do processo de ensino e aprendizagem. A autora traz, ao término, um glossário considerável e aponta atuais e válidas referências.

Após a leitura atenta do livro de Denise Bértoli Braga, fica a impressão de que a obra alcança plenamente seu objetivo: instigar pesquisadores e docentes do Ensino Médio, sobretudo professores de línguas, a reflexões, levando-os, enfim, a admitirem o potencial e utilizarem as TICs e seus ambientes digitais na atuação profissional. O livro apresenta alguns detalhes de revisão, que nem de longe ofuscam seu brilho temático e sua solidez de abordagem. Tratase de minúcia a ser naturalmente sanada em uma próxima e merecedora edição. "Ambientes digitais: reflexões teóricas e práticas" é um manual prodigioso para professores desse nível de ensino; obra promotora de um novo pensar acerca dos ambientes digitais na escola e na sociedade. A linguagem descolada e descontraída da autora traduz-se na eficácia e assertividade de seu discurso. Em tempos de uma sociedade em rede, globalizada e tecnológica, o legado da autora é realmente um passo inicial muito bem dado para a transformação da concepção pedagógica quanto aos insofismáveis letramentos digitais. Realmente, navegar é preciso!

\section{Sobre os autores:}

Acir Mário Karwoski: Doutor em Letras (Estudos Linguísticos) pela Universidade Federal do Paraná (UFPR); Professor adjunto no curso de Letras e no programa de pós-graduação Mestrado em educação da Universidade Federal do Triângulo Mineiro (UFTM) - Uberaba - MG. E-mail: acirmario@letras.uftm.edu.br .

Julio Cesar Oliveira Bernardo: Licenciado em Letras. Professor da Educação Básica. Especialista em Metodologia de Ensino da Língua Portuguesa. Técnico em Assuntos Educacionais na Universidade Federal do Triângulo Mineiro (UFTM) - Uberaba - MG. E-mail: juliobernar78@ hotmail.com.

Resenha recebida em novembro de 2013

Resenha aprovada em dezembro de 2013 